\title{
GRO- $\alpha$ in normal and pathological thyroid tissues and its regulation in thyroid-derived cells
}

\author{
G Aust, M Steinert ${ }^{1}$, C Boltze ${ }^{2}$, S Kießling and C Simchen \\ Institute of Anatomy, University of Leipzig, Germany \\ ${ }^{1}$ Department of Surgery, University of Leipzig, Germany \\ ${ }^{2}$ Institute of Pathology, University of Magdeburg, Germany \\ (Requests for offprints should be addressed to G Aust, University of Leipzig, Institute of Anatomy, Liebigstr.13, Leipzig 04103, Germany; \\ Email: ausg@medizin.uni-leipzig.de)
}

\begin{abstract}
Thyroid glands affected by Graves' disease (GD) show striking leukocytic infiltration, mainly by $\mathrm{T}$-cells. The mechanisms by which the various leukocytes are maintained in the thyroid are unknown. Growth-regulated oncogene- $\alpha(\mathrm{GRO}-\alpha)$ in interaction with its receptor CXCR2 is a chemoattractant for both T-cells and neutrophils and may be one of the chemokines involved in the cell maintenance.

GRO- $\alpha$ and CD18 mRNA as a marker of leukocytic infiltration were quantified in thyroid tissue using competitive RT-PCR. We found very high GRO- $\alpha$ mRNA levels in all thyroid tissues. In GD patients $(n=16)$, the GRO- $\alpha$ mRNA did not correlate with the CD18 mRNA level or thyroid peroxidase and TSH-receptor antibodies in patients' sera. In thyroid autonomy $(n=10)$, the
\end{abstract}

GRO- $\alpha$ mRNA levels were significantly lower in autonomous single adenomas compared with the corresponding normal tissue.

In order to define the cellular source of GRO- $\alpha$ mRNA and protein, we examined various thyroidderived cells. Thyrocytes, thyroid-derived leukocytes and fibroblasts showed basal GRO- $\alpha$ mRNA and protein expression, which was remarkably upregulated by different stimuli in vitro. The expression of GRO- $\alpha$ by thyroid carcinoma cell lines confirms that thyrocytes may actually produce GRO- $\alpha$. As shown by flow cytometry and immunohistology, $\mathrm{CD} 68^{+}$monocytes/macrophages are the only cell population strongly expressing CXCR 2 in the thyroid.

Journal of Endocrinology (2001) 170, 513-520

\section{Introduction}

Chemokines mediate the precise and selective trafficking and maintenance of immune cells in normal and pathological tissues, act during morphogenesis, and affect angiogenesis and the proliferation of haematopoetic precursors (Baggiolini 1998, Belperio et al. 2000). The superfamily of chemokines is divided into groups based on structural and genetic considerations and have been termed the CXC, CC, C and CX3C families.

Only a few reports have been published on the expression of chemokines in the thyroid, although they are involved in various thyroid disorders. Ashhab et al. (1999) showed a significantly higher expression of various CC chemokine mRNAs in thyroid glands affected by Graves' disease (GD) compared with non-autoimmune thyroid disorders. We found a clear correlation between the intensity of lymphocyte infiltration and the level of RANTES (regulated on activation, normal $\mathrm{T}$ cells expressed and secreted), a T-cell and monocyte attracting chemokine, in thyroid tissues from GD patients (Simchen et al. 2000). In patients with thyroid autonomy (TA), autonomous nodules contained significantly lower levels of the unique chemokine stromal-derived factor-1 (SDF-1) compared with the corresponding normal tissue of the same patient (Aust et al. 2001). SDF-1 keeps similar cells together and provides tissue homeostasis.

The CXC chemokine growth-regulated oncogene- $\alpha$ (GRO- $\alpha$ )/melano growth stimulatory activity (MGSA) was originally isolated as an autocrine growth factor from a human melanoma cell line (Richmond \& Thomas 1988). It can be produced in response to proinflammatory cytokines in a variety of cell types such as epithelial, smooth muscle and endothelial cells, fibroblasts, macrophages and tumour cell lines of varying origin (Vaddi et al. 1997). GRO- $\alpha$ is a powerful activator of neutrophils and induces chemotaxis, exocytosis, and the respiratory burst in vitro and accumulation of neutrophils in vivo. However, neutrophils have not been demonstrated among the thyroidinfiltrating leukocytes, although functional changes have been described for peripheral neutrophils in GD patients (Wolach et al. 1989). Surprisingly, Jinquan et al. (1995) have found that GRO- $\alpha$ is also a powerful chemoattractant for isolated T-cells. The migrating T-lymphocytes' 
Table 1 Basal and stimulated GRO- $\alpha$ protein (mean \pm S.E.M., $n$ 4) in thyroid carcinoma cell lines measured by ELISA (pg/ml)

\begin{tabular}{|c|c|c|c|c|c|}
\hline & Basal & PMA & LPS & II-1 & TNF- $\alpha$ \\
\hline FTC 133 & $1132 \pm 184$ & $1703 \pm 320^{*}$ & $1134 \pm 360$ & $9924 \pm 258 *$ & $2940 \pm 215^{*}$ \\
\hline SW 1736 & $390 \pm 36$ & $7602 \pm 991^{*}$ & $516 \pm 20$ & $7655 \pm 254^{*}$ & $2533 \pm 247^{*}$ \\
\hline 8505 C & $19670 \pm 4127$ & $14660 \pm 900 *$ & $30792 \pm 5358^{*}$ & $26521 \pm 2440^{*}$ & $22640 \pm 5013$ \\
\hline
\end{tabular}

$P<0 \cdot 01$ compared to basal levels.

phenotype predominantly comprises $\mathrm{CD} 45 \mathrm{RO}^{+}$memory $\mathrm{CD}^{+}$and $\mathrm{CD}^{+}$subsets. The CD18 ${ }^{+}$leukocytic infiltrate in GD consists of CD45RO ${ }^{+} \mathrm{T}$ cells (Martin et al. 1990, Aust et al. 1996) at over 70\%. Thus, GRO- $\alpha$ may be involved in the maintenance of the leukocytic infiltrate in GD.

Analysing the trafficking and selective accumulation of leukocyte subsets in the pathophysiology of autoimmune diseases such as multiple sclerosis and insulin-dependent diabetes supports the essential role of the chemokine/ chemokine receptor network in this process (Arimilli et al. 2000). To date, GRO- $\alpha$ has been analysed only once in experimental allergic encephalomyelitis (EAE), the animal model of multiple sclerosis. Here, GRO- $\alpha$ was upregulated simultaneously with symptom onset of acute EAE, and correlates with the intensity of inflammation in the central nervous system (Glabinski et al. 1998).

The aim of our study was to investigate the expression of GRO- $\alpha$ mRNA in thyroid tissue affected by GD and TA. Not only is no information available on the expression of GRO- $\alpha$ and its receptor CXCR2 in the thyroid under normal and pathological conditions, but their cellular sources and regulation are also unknown. Thus, we isolated thyroid-derived lymphocytes, fibroblasts and thyrocytes and, in addition to four thyroid carcinoma cell lines, checked for their basal and stimulated capacity to express GRO- $\alpha$ in vitro at the mRNA and protein levels. The expression of the only GRO- $\alpha$ binding receptor, CXCR2, was examined by immunohistology and flow cytometry.

\section{Materials and Methods}

\section{Patients}

The patients in the study were diagnosed for GD (2 male, 14 female, mean age \pm s.E.M.: $40 \cdot 8 \pm 2 \cdot 8$ years) and TA ( $n=10$, all female, $57 \cdot 2 \pm 2 \cdot 7$ years) on the basis of clinical, biochemical and immunological features, as well as from scintiscans. Fourteen out of sixteen GD patients who had been treated with methimazole or propylthiouracil for more than eight months were clinically euthyroid, having normal free thyroxine and tri-iodothyronine levels at the time of operation. Two of the patients were undergoing surgery within two months after diagnosis without anti- thyroid drug treatment. Pertechnetate showed a single hot nodule with a low uptake in the rest of the thyroid in all patients with unifocal TA thyroid scans using $99 \mathrm{~m}$ Tc. Consent has been obtained from each patient after full explanation of the purpose and the nature of our study. The investigation was approved by the local ethical committee, functioning according to the guidelines issued by the Royal College of Physicians, London.

Antibodies against the thyrotrophin (TSH)-receptor (TSH-binding inhibiting immunoglobulin) and thyroid peroxidase (TPO) were measured in serum obtained with RIA kits (BRAHMS Diagnostica GmbH, Berlin, Germany) during the two weeks before operation. GD patients could be divided further into patients with high $(>4000 \mathrm{U} / \mathrm{ml})$ and patients with low $(<200 \mathrm{U} / \mathrm{ml})$ or zero serum anti-TPO levels.

Thyroid samples from the patients were obtained during operation. In TA, the tissue was carefully separated into adenomatous and quiescent tissue. The samples were frozen and stored in liquid nitrogen until required or were formalin fixed. The number of leukocytes was graded semiquantitatively by immunohistology as described by Simchen et al. (2000). For molecular assessment of leukocytic infiltration, tissue samples were quantified for CD18 mRNA (see below for method) (Aust et al. 2001). We found a correlation between histological and molecular determination of leukocytes $(r=0 \cdot 66, P=0 \cdot 01)$. Thus, only the results for CD18 mRNA quantitation in tissue samples are shown in Table 1. Spearman's method was used to calculate the correlation between GRO- $\alpha$ mRNA, serum TPO and TSH-receptor antibodies, and CD18 mRNA levels.

\section{Preparation of thyroid-derived cells and cell lines}

Thyroid-derived cells were prepared from three thyroids of patients with GD. Thyrocytes and leukocytes, almost exclusively consisting of lymphocytes, were enriched and purified after gradual enzymatic tissue digestion as described (Aust et al. 1997). By culturing small pieces of thyroid tissue, outgrowing fibroblasts were obtained, harvested, and used in the 5th-7th passage. The human anaplastic thyroid carcinoma lines SW 1736 and HTh 74 (kindly provided by Dr N-E Heldin, University of Uppsala, Sweden), $8505 \mathrm{C}$ and the follicular carcinoma 
line FTC-133 (DSMZ, Braunschweig, Germany) were cultured in DMEM/10\% FCS.

\section{In vitro cultures and detection of GRO- $\alpha$}

Cells $\left(1 \times 10^{5}\right.$ cells/well $)$ were cultured on 24 -well plates for $24 \mathrm{~h}$. The medium was aspirated and replaced with $500 \mu \mathrm{l}$ OPTI-MEM (Gibco Life Technologies GmbH, Karlsruhe, Germany) without FCS. The medium contained the desired concentration of human interleukin- $1 \alpha$ (IL-1 $\alpha ; 10 \mathrm{U} / \mathrm{ml}$ ), tumour necrosis factor- $\alpha$ (TNF- $\alpha$; $5 \mathrm{ng} / \mathrm{ml}$ ), lipopolysaccharide E. coli 055:B5 (LPS; $100 \mathrm{ng} /$ $\mathrm{ml}$ ), or $10 \mathrm{ng} / \mathrm{ml}$ phorbol myristateacetate (PMA; Sigma, Deisenhofen, Germany). For each stimulator, triplicate cultures were analysed. The maximum or plateau values for GRO- $\alpha$ mRNA $(6 \mathrm{~h})$ and protein expression (24 h) were determined with HTh 74 cells taken as a standard. In leukocytes, the GRO- $\alpha$ mRNA and protein levels were examined after 6 and $12 \mathrm{~h}$, as the cells died after this time without stimulation. The supernatants were assayed for GRO- $\alpha$ by ELISA ( $\mathrm{R} \& \mathrm{D}$ Systems, Wiesbaden, Germany). The protein levels of cultures obtained from separate experiments were presented as means \pm s.E.M. The Mann-Whitney test was used to determine the statistically significant difference between basal and stimulated cells. Additionally, $3 \times 10^{4}$ cells were seeded into eight-well chamber slides, cultured and stimulated with IL-1 as described above. After fixation, endogenous peroxidase activity was quenched in $0 \cdot 3 \% \mathrm{H}_{2} \mathrm{O}_{2}$ in methanol for $15 \mathrm{~min}$. The cells were stained with a polyclonal goat anti-GRO- $\alpha$ antibody (R \& D Systems) followed by rabbit anti-mouse biotin and streptavidin-horseradish peroxidase (ABC standard, Vector Laboratories, Burlingame, CA, USA) and developed with diaminobenzidine hydrochloride (DAB). Blocking controls created by preincubating $1 \mu \mathrm{g}$ antibody with $50 \mathrm{ng}$ GRO- $\alpha$ (R \& D Systems) were included.

For RT-PCR, $0.2 \mathrm{ml}$ lysis buffer from the total RNA isolation kit (Qiagen $\mathrm{GmbH}$, Hilden, Germany) was added to each well, and the contents of three wells were then pooled.

\section{$R N A$ isolation and $c D N A$ synthesis}

Total cellular RNA was isolated from thyroid tissue and cell cultures with the total RNA isolation kit (Qiagen) in accordance with the manufacturer's instructions. Five micrograms total RNA were taken to synthesise cDNA using a first-strand cDNA synthesis kit from Amersham Pharmacia Biotech (Freiburg, Germany) in a reaction volume of $15 \mu \mathrm{l}$.

\section{Semiquantitative competitive RT-PCR}

To quantify human GRO- $\alpha$ and CD18 cDNA, a rapid one-step method was introduced to synthesise internal homologous competitors (Aust et al. 1997). For example, amplification of thyroid tissue cDNA with the GRO- $\alpha$ sense $\left(5^{\prime}-\operatorname{ctg} \operatorname{cgc} c c a\right.$ aac cga agt $\left.c-3^{\prime}\right)$ and GRO- $\alpha$ hybrid $\left(5^{\prime}-\right.$ atc $\mathrm{cgc}$ cag cet cta tca cag aag at gaa tat aat agg aca gtg $\left.-3^{\prime}\right)$ primers resulted in a $385 \mathrm{bp}$ GRO- $\alpha$ competitor (CD18 sense: $5^{\prime}-$ ggc gca caa gct ggc tga aaa caa $-3^{\prime}$, hybrid: $5^{\prime}-$ agc gcc cgg atg aca aac gac tgg aca ttg atc tgc acg cca tc $-3^{\prime} ; 323$ bp competitor).

Variations between different cDNA preparations were corrected. All the samples were first adjusted to contain equal concentrations of glyceraldehyde-3-phosphate dehydrogenase (GAPDH) cDNA in a semiquantitative RTPCR (Aust et al. 1997). We then estimated GRO- $\alpha$ and CD18 cDNA in these adjusted samples. cDNA samples were titrated into RT-PCR amplification solutions containing known copies of the competitor. Both the sample cDNA and the competitor were co-amplified using the same sense and antisense primers (antisense; GRO- $\alpha$ : $5^{\prime}$ - atc cgc cag cct cta tca cag -3', CD18: $5^{\prime}-$ agc gec cgg atg aca aac gac tg $\left.-3^{\prime}\right)$. Two products were generated. One was derived from the cDNA (GRO- $\alpha$ : $520 \mathrm{bp}$; CD18: $372 \mathrm{bp}$ ) and the other, smaller in size, from the competitor. Based on the difference in length, the sample cDNA and competitor PCR products were resolved by gel electrophoresis. The sample cDNA and competitor were quantified by measuring the intensity of ethidium fluorescence as described by Simchen et al. (2000). Each $25 \mu \mathrm{l}$ amplification reaction contained $2.5 \mu \mathrm{l} 10 \times$ concentrated PCR buffer $\left(15 \mathrm{mM} \mathrm{MgCl}_{2}\right), 0 \cdot 3 \mathrm{U}$ Taq DNA polymerase (Roche Molecular Biochemicals, Mannheim, Germany), $100 \mu \mathrm{M}$ dNTPs, $0 \cdot 1 \mu \mathrm{M}$ of each primer, $1 \mu \mathrm{l}$ sample cDNA and the stabilised competitor in adjusted dilutions.

\section{CXCR2 receptor analysis}

Cells $\left(2 \times 10^{5}\right)$ were stained with fluorochrome-labelled antibodies at the desired concentration at $4{ }^{\circ} \mathrm{C}$ for $25 \mathrm{~min}$ (CXCR2-PE, CD3-Cy5; R \& D Systems) and were analysed by FACSscan (Becton Dickinson, Mountain View, CA, USA). CXCR2 expression was examined further on formalin fixed and paraffin embedded thyroid sections with a thickness of $3 \mu \mathrm{m}$, after treatment in a microwave for $2 \mathrm{~min}$. After deparaffinisation, the sections were placed into citrate buffer $(\mathrm{pH} 6.0)$ and steamed for $15 \mathrm{~min}$ for epitope enhancement. Serial sections were stained with CXCR2 (clone 10H2, a kind gift from Dr Chuntharapai, Genentech Inc., South San Francisco, CA, USA) (Tecimer et al. 2000), CD3 (T-cells), CD68 (monocytes/macrophages) and calcitonin (C-cells) antibodies (Dako Diagnostika GmbH, Hamburg, Germany) by an automated immunohistochemical system (VentanaBiotech, Tucson, AZ, USA) using their standard ABC method. CXCR 2 was developed using DAB, while CD3, CD68 and calcitonin were developed with Neofucsin as a chromogen (Sigma). The slides were evaluated using 


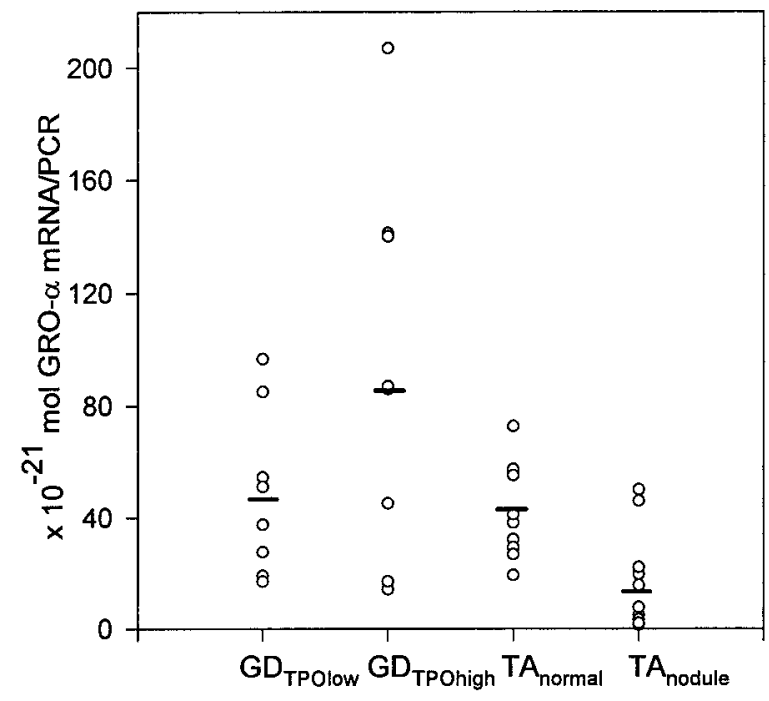

Figure 1 GRO- $\alpha$ mRNA levels in the thyroid tissue of patients with GD showing none or low $(\leq 200 \mathrm{U} / \mathrm{ml})$ and high $(\geq 4000 \mathrm{U} / \mathrm{ml})$ levels of TPO antibodies in the serum and in autonomous nodules and the quiescent surrounding tissue of patients with TA.

the Interactive Measurement module of the AxioVision system (Zeiss, Jena, Germany).

\section{Results}

GRO-a mRNA levels in thyroid tissues

All thyroid tissues were positive for GRO- $\alpha$ and CD18 mRNA. In GD patients, we confirmed the known correlation between leukocytic infiltration and TPO antibodies $(r=0.87 ; \quad P<0 \cdot 005)$. However, the GRO- $\alpha$ mRNA level did not correlate with either CD18 mRNA levels or TPO and TSH-receptor antibodies. The GRO- $\alpha$ mRNA levels varied considerably in patients with high TPO antibodies and high CD18 mRNA levels (Fig. 1). In TA, the GRO- $\alpha$ mRNA levels differed significantly between autonomous single adenomas and the corresponding normal tissue $(P<0 \cdot 05)$. In 8 out of 10 patients, GRO- $\alpha$ mRNA levels in the nodule were lower compared with those of the normal tissue (Fig. 1). Although CD18 mRNA levels were significantly lower in the nodules (mean \pm s.E.M.; $\times 10^{-21} \mathrm{~mol}$ CD18 cDNA/ PCR; $106 \pm 36)$ compared with normal tissue (192 \pm 65 ), there was no correlation between the CD18 and GRO- $\alpha$ mRNA levels, which was mainly due to the high variations in both tissue sides.

\section{GRO- $\alpha$ expression in thyroid-derived cells}

Thyrocytes, leukocytes and fibroblasts expressed and secreted GRO- $\alpha$ under basal conditions (Figs 2-4). Each

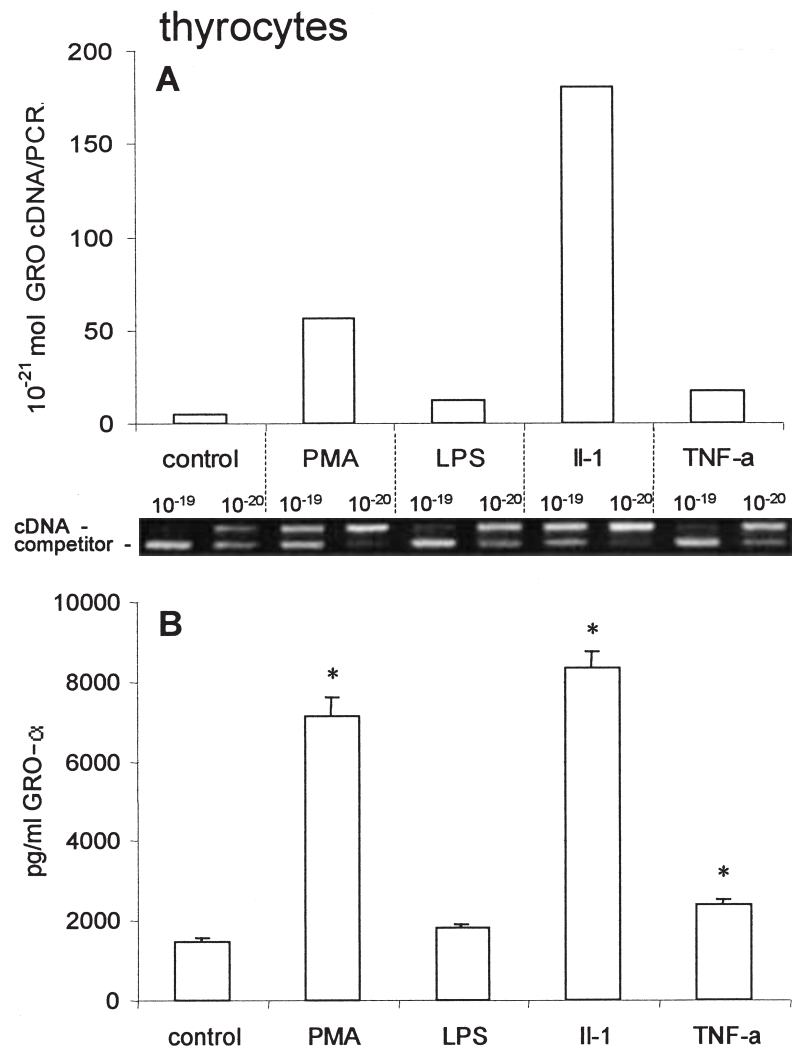

Figure 2 GRO- $\alpha$ mRNA and protein in stimulated cultures of thyrocytes. (A) Semiquantitative RT-PCR. The GRO- $\alpha$ competitor (only shown at $10^{-20}$ and $10^{-19} \mathrm{~mol} / \mathrm{PCR}$ ) was coamplified with the sample cDNA in the same PCR tube. Both PCR products were separated by gel electrophoresis and quantified. One out of three representative experiments is shown. (B) GRO- $\alpha$ determined in cell supernatants by ELISA $(n=4)$. * Significant difference between basal and stimulated RANTES levels, $P<0 \cdot 05$.

cell population responded to other stimuli. TNF- $\alpha$, and particularly IL-1, increased GRO- $\alpha$ mRNA and protein in fibroblasts. GRO- $\alpha$ mRNA and protein expression in leukocytes may mainly be effected by monocytes/ macrophages, as LPS significantly increased GRO- $\alpha$. In thyrocytes, PMA and IL-1 caused an increase of up to 100 -fold in GRO- $\alpha$ mRNA and a three- to fivefold increase in GRO- $\alpha$ protein.

To confirm that thyrocytes may actually produce GRO- $\alpha$, we examined four thyroid carcinoma cell lines. All of them expressed GRO- $\alpha$ mRNA and protein under basal conditions, but the levels varied considerably (Table 1). Unstimulated $8505 \mathrm{C}$ cells secreted GRO- $\alpha$ at up to $20 \mathrm{ng} / \mathrm{ml}$. We found a good correlation between basal/stimulated mRNA and basal/stimulated protein levels (data not shown). Each of the cell lines responded to other stimuli.

Immunostaining of cultured thyrocytes (Fig. 5) and fibroblasts (data not shown) confirmed the results obtained 


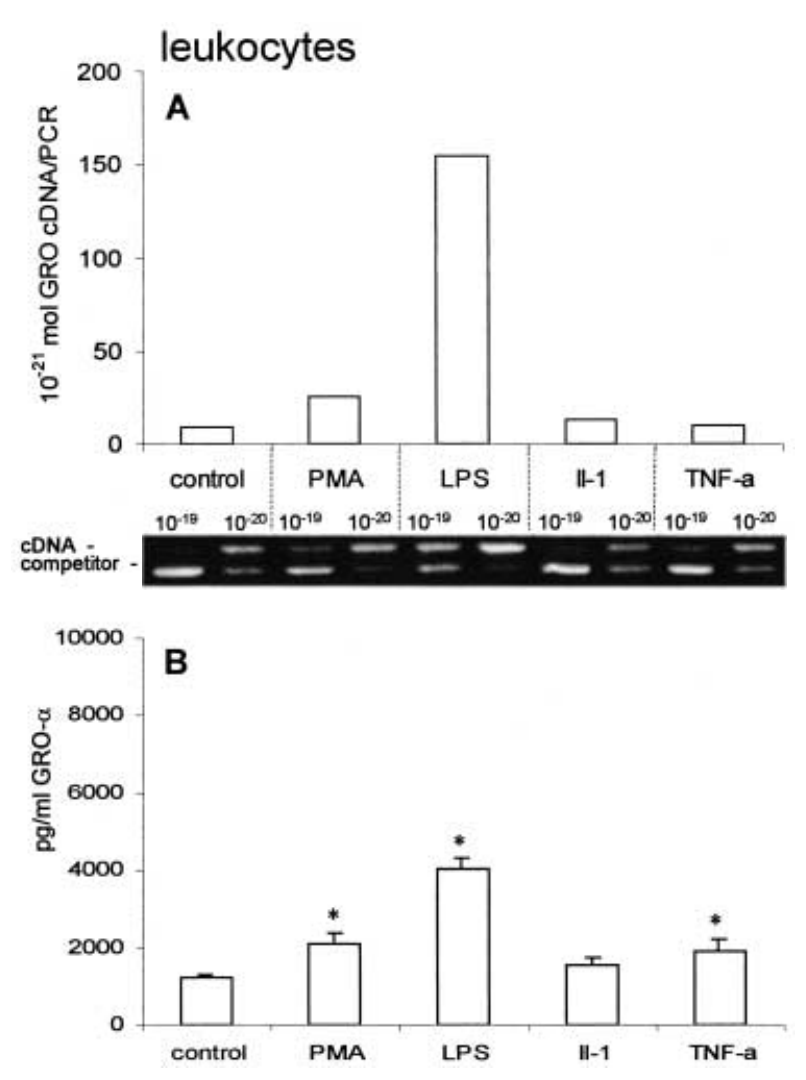

Figure 3 GRO- $\alpha$ mRNA (A) and protein (B) in stimulated cultures of thyroid-derived leukocytes. Details as in Fig. 2. ${ }^{*}$ Significant difference between basal and stimulated RANTES levels, $P<0 \cdot 05$.

from the GRO- $\alpha$ ELISA and semiquantitative GRO- $\alpha$ RT-PCR. GRO- $\alpha$ was faintly expressed in unstimulated thyrocytes (Fig. 5A) and fibroblasts (not shown). Activation of the cells with IL-1 resulted in stronger staining for GRO- $\alpha$ (Fig. 5B). Preincubation of the anti-GRO- $\alpha$ antibody with GRO- $\alpha$ completely abolished immunostaining in activated cells (Fig. 5C).

\section{CXCR2 expression}

In flow cytometry, thyrocytes, all cell lines, and fibroblasts were CXCR2 negative. Analysing thyroid-derived leukocytes, $\mathrm{CD}^{+}$cells did not express CXCR2. Only the few monocytes/macrophages among the leukocytes were CXCR2 positive (data not shown).

The results were confirmed by immunohistology. Serial sections labelled with CD3, CD68 and calcitonin antibodies were used to characterise the $\mathrm{CXCR}^{+}$cells. Using higher concentrations of the CXCR2 antibody, we could show that scattered individual cells and groups of cells in follicles and interstitium expressed CXCR2 (Fig. 5D). Co-localisation with the anti-calcitonin antibody (Fig. 5E) showed that these cells are C-cells.

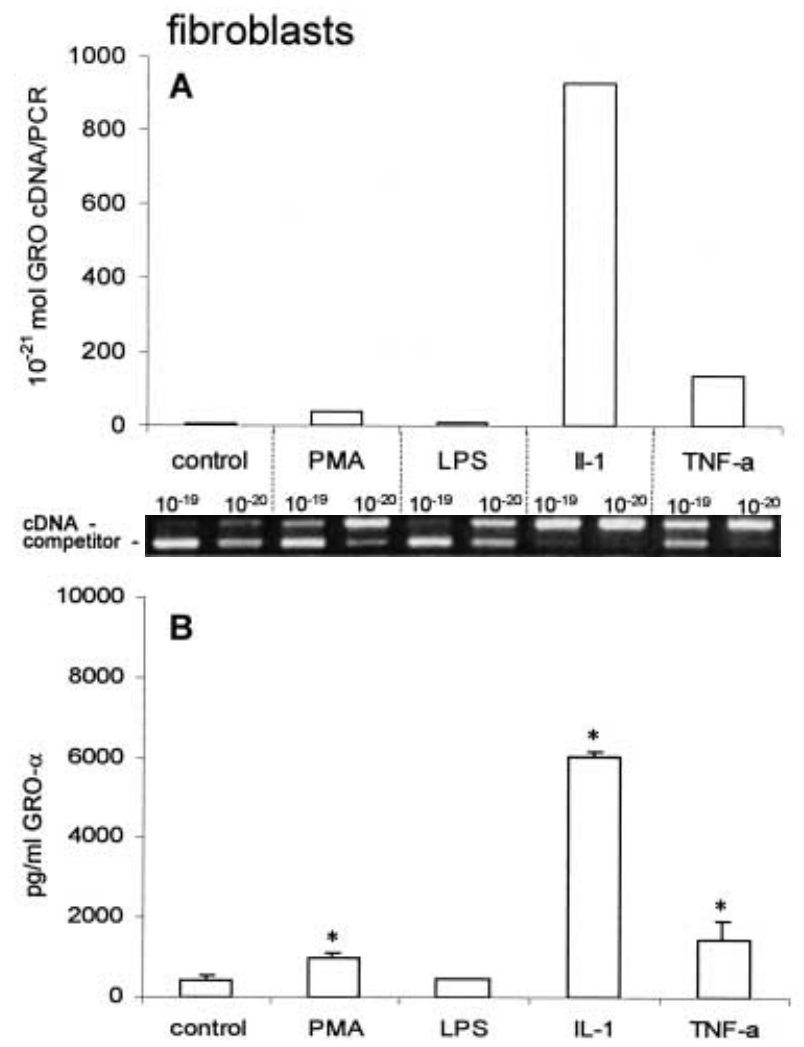

Figure 4 GRO- $\alpha$ mRNA (A) and protein (B) in stimulated cultures of thyroid-derived fibroblasts. Details as in Fig. 2. *Significant difference between basal and stimulated RANTES levels, $P<0 \cdot 05$.

Also, strongly CXCR2-stained cells were typically located within lymphoid accumulations and within the interstitium, indicating that these cells are macrophages (Fig. 5F). Superposition of the pictures obtained from serial sections with CD68 and CXCR2 antibodies confirmed this assumption (Fig. 5G). Staining with lower concentrations of CXCR 2 labelled only $\mathrm{CD}^{+} 8^{+}$cells strongly. The results indicate various densities of CXCR2 on C-cells and monocytes/macrophages. T- and B-cells, thyrocytes, fibroblasts and endothelial cells were CXCR2 negative in all tissues examined, independent of the underlying pathogenesis.

\section{Discussion}

This is the first study showing high GRO- $\alpha$ mRNA expression in thyroid tissues. We found differences in GRO- $\alpha$ mRNA between autonomous nodules and the corresponding normal tissue, but, as was the case in tissues affected by GD, there was no correlation between leukocytic infiltration and GRO- $\alpha$ mRNA. The result raises the question about the function of GRO- $\alpha$ in normal and pathological thyroid tissues. First, besides its properties 

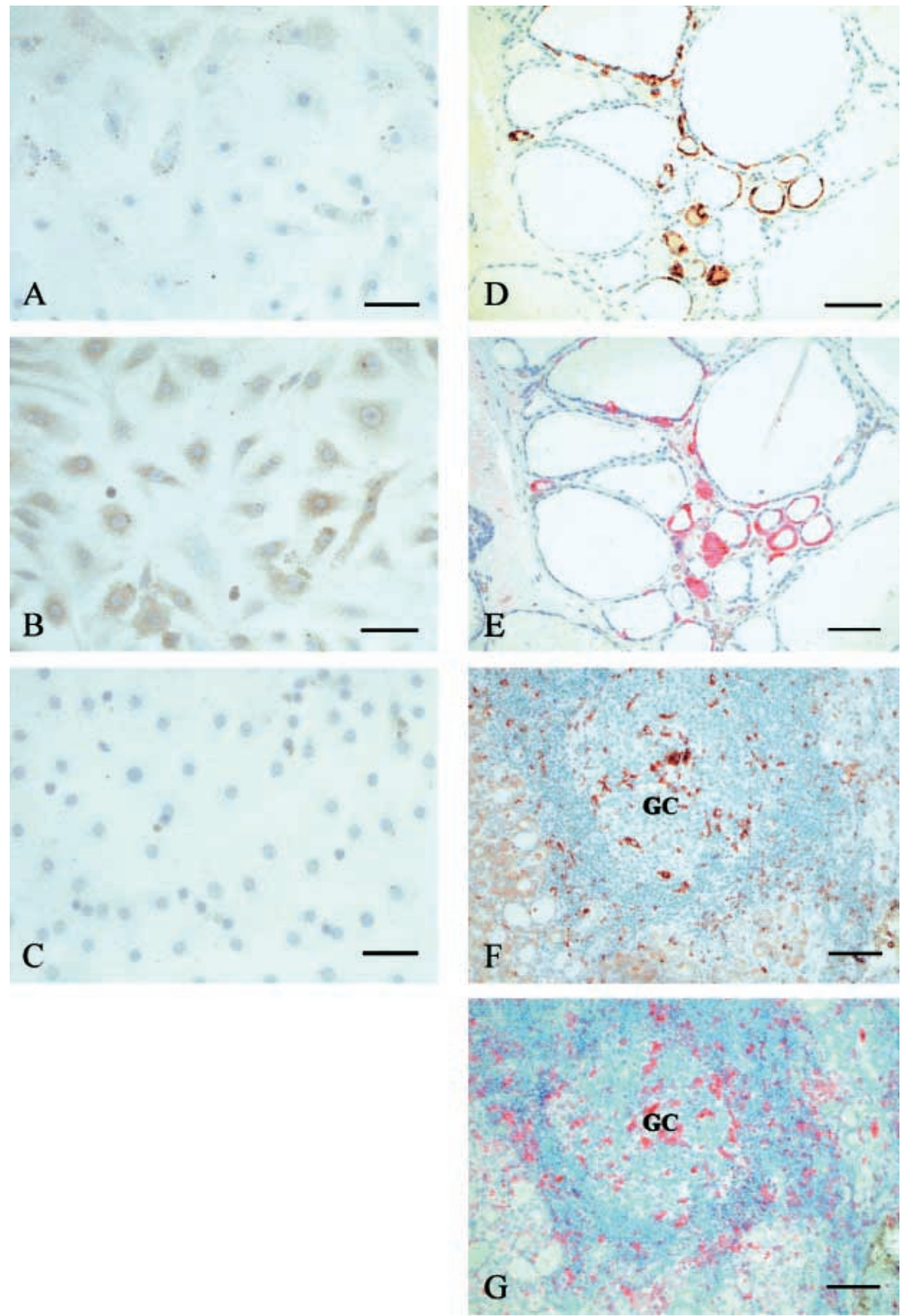

Figure 5 (A-C) Immunostaining of cultured thyrocytes. (A) GRO- $\alpha$ was faintly expressed in unstimulated cells, whereas activation with IL-1 caused a stronger staining for GRO- $\alpha$ (B). GRO- $\alpha$ staining could be completely blocked by preincubating $1 \mu$ g of the anti-GRO- $\alpha$ antibody with $50 \mathrm{ng}$ GRO- $\alpha(\mathrm{C})$. Scale bar $50 \mu \mathrm{m}$. (D-G) Immunostaining of cryostat sections from a thyroid gland of a patient with GD. Serial sections stained with CXCR2 (D) and anti-calcitonin (E) antibodies showed that C-cells are CXCR2 positive. Moreover, CXCR2 (F) and CD68 (G) antibodies show identical staining patterns in secondary follicles, confirming that macrophages express CXCR2. Cells scattered between the follicles or located in aggregates also express CXCR2. Furthermore, cells located within the germinal centre (GC) and the mantle zone of secondary follicles were CXCR2 positive. Scale bar $100 \mu \mathrm{m}$. 
on neutrophils, GRO- $\alpha$ is similar to RANTES in its efficiency for T-lymphocyte chemotaxis, but apparently has much higher potency (Jinquan et al. 1995). However, our results indicate that GRO- $\alpha$ does not play a key role in the complex network of individual chemokines and receptors capable of maintaining the selective thyroid infiltrate. Secondly, the GRO- $\alpha$ mRNA level may correlate to angiogenic activity in the tissues, as GRO- $\alpha$ belongs to the CXC chemokines containing the ELRmotif, which have been found to be potent angiogenic factors (Belperio et al. 2000). Iitaka et al. (1998) described increased vascular endothelial growth factor levels and intrathyroidal vascular areas in patients with GD. Unfortunately, the ratio of intrathyroidal vascular to thyroid area that has to be correlated to GRO- $\alpha$ mRNA levels could not be determined retrospectively in our conserved tissue samples.

GRO- $\alpha$ expression in the thyroid is not limited to one cell population. Leukocytes, thyrocytes and fibroblasts participate in GRO- $\alpha$ expression, and may upregulate the chemokine after stimulation. It is interesting that thyrocytes produce GRO- $\alpha$ under basal conditions. Although it is well known that thyrocytes produce a greater variety of cytokines in vitro than any other endocrine cells (Aust \& Scherbaum 1996), only a few chemokines produced by thyrocytes have been found. Untreated thyrocytes secrete IL-8, the other chemokine that binds to the same receptor as GRO- $\alpha$, CXCR2 (Weetman et al. 1992). Both GRO- $\alpha$ and IL- 8 were strongly upregulated by IL-1, which is highly expressed in the thyroid. Monocyte chemoattractant protein-1 is a chemokine that attracts T-lymphocytes as well as monocytes, and can also be produced by thyrocytes (Kasai et al. 1996). All these studies suggest a possible role of thyrocytes on accumulation of leukocytes into the tissue from the blood. To confirm our observations on GRO- $\alpha$ in thyrocytes, we examined four thyroid carcinoma cell lines. The results indicate that thyrocytes can maintain or even upregulate GRO- $\alpha$ expression after malignant transformation. The prostate cancer cell line Du145 has been shown to use GRO- $\alpha$ to mediate tumorigenicity by stimulating angiogenesis (Moore et al. 1999). Neutralising antisera to GRO- $\alpha$ reduced tumour growth in vivo and the angiogenic activity in tumour homogenates. Thus, GRO- $\alpha$ secretion by thyroid carcinoma cells may be involved in tumour growth.

The distribution of CXCR2 only gave a first insight into the function of GRO- $\alpha$ in the thyroid since although GRO- $\alpha$ only mediates its action via CXCR2, this receptor may bind other CXC chemokines (Premack \& Schall 1996). Probably, all monocytes/macrophages express CXCR2 in the thyroid. We could confirm the expression of CXCR2 on thyroid C-cells as observed by Tecimer et al. (2000) using a highly concentrated antibody. This indicates varying densities of the antigen on both cell types. Apart from that, thyroid-derived T-lymphocytes were CXCR2-negative in immunohistology. The existence of CXCR2 receptors on T-lymphocytes has been disputed for a long time, as CXCR 2 could not be detected using different methods, but antibodies to CXCR2 block the chemotaxis of T-lymphocytes towards GRO- $\alpha$ (Jinquan et al. 1995). Maybe, T-lymphocytes only express CXCR2 in very low numbers, which are however sufficient to attract these cells towards GRO- $\alpha$.

Taken together, GRO- $\alpha$ has been found in normal and pathological thyroid tissue at high levels. The chemokine may be produced by a variety of cell types in the thyroid.

\section{Acknowledgements}

We would like to thank Mrs D Sittig for technical assistance and Prof. K Spanel-Borowski for her expert advice. The study was financially supported by the IZKF, project B6, University of Leipzig.

\section{References}

Arimilli S, Ferlin W, Solvason N, Deshpande S, Howard M \& Mocci S 2000 Chemokines in autoimmune diseases. Immunological Reviews $17743-51$.

Ashhab Y, Dominguez O, Sospedra M, Roura-Mir C, Lucas-Martin A \& Pujol-Borrell R 1999 A one-tube polymerase chain reaction protocol demonstrates CC chemokine overexpression in Graves' disease glands. Journal of Clinical Endocrinology and Metabolism 84 2873-2882.

Aust G \& Scherbaum WA 1996 Expression of cytokines in the thyroid: thyrocytes as potential cytokine producers. Experimental and Clinical Endocrinology and Diabetes 104 64-67.

Aust G, Lehmann I \& Heberling H-J 1996 Different immunophenotype and autoantibody production by peripheral blood and thyroid-derived lymphocytes in patients with Graves' disease. Experimental and Clinical Endocrinology and Diabetes 104 52-60.

Aust G, Hofmann A, Laue S, Rost A, Köhler T \& Scherbaum WA 1997 Human thyroid carcinoma cell lines and normal thyrocytes: expression and regulation of MMP-1 and TIMP-1 mRNA and protein. Thyroid 7 713-724.

Aust G, Steinert M, Kiessling S, Kamprad M \& Simchen C 2001 Reduced expression of SDF-1 in autonomous thyroid adenomas (TA) and its regulation in thyroid-derived cells. Journal of Clinical Endocrinology and Metabolism 86 3368-3376.

Baggiolini M 1998 Chemokines and leukocyte traffic. Nature 392 565-568.

Belperio JA, Keane MP, Arenberg DA, Addison CL, Ehlert JE, Burdick MD \& Strieter RM 2000 CXC chemokines in angiogenesis. Journal of Leukocyte Biology 68 1-8.

Glabinski AR, Tuohy VK \& Ransohoff RM 1998 Expression of chemokines RANTES, MIP-1 alpha and GRO-alpha correlates with inflammation in acute experimental autoimmune encephalomyelitis. Neuroimmunomodulation 5 166-171.

Iitaka M, Miura S, Yamanaka K, Kawasaki S, Kitahama S, Kawakami Y, Kakinuma S, Oosuga I, Wada S \& Katayama S 1998 Increased serum vascular endothelial growth factor levels and intrathyroidal vascular area in patients with Graves' disease and Hashimoto's thyroiditis. Journal of Clinical Endocrinology and Metabolism $\mathbf{8 3}$ 3908-3912.

Jinquan T, Frydenberg J, Mukaida N, Bonde J, Larsen CG, Matsushima K \& Thestrup-Pedersen K 1995 Recombinant human 
growth-regulated oncogene-alpha induces $\mathrm{T}$ lymphocyte chemotaxis. A process regulated via IL- 8 receptors by IFN-gamma, TNF-alpha, IL-4, IL-10, and IL-13. Journal of Immunology 155 5359-5368.

Kasai K, Banba N, Motohashi S, Hattori Y, Manaka K \& Shimoda SI 1996 Expression of monocyte chemoattractant protein-1 mRNA and protein in cultured human thyrocytes. FEBS Letters 394 137-140.

Martin A, Goldsmith NK, Friedman EW, Schwartz AE, Davies TF \& Roman SH 1990 Intrathyroidal accumulation of T cell phenotypes in autoimmune thyroid disease. Autoimmunity 6 269-281.

Moore BB, Arenberg DA, Stoy K, Morgan T, Addison CL, Morris SB, Glass M, Wilke C, Xue YY, Sitterding S, Kunkel SL, Burdick MD \& Strieter RM 1999 Distinct CXC chemokines mediate tumorigenicity of prostate cancer cells. American Journal of Pathology 154 1503-1512.

Premack BA \& Schall TJ 1996 Chemokine receptors: gateways to inflammation and infection. Nature Medicine 2 1174-1178.

Richmond A \& Thomas HG 1988 Melanoma growth stimulatory activity: isolation from human melanoma tumors and characterization of tissue distribution. Journal of Cellular Biochemistry 36 185-198.

Simchen C, Lehmann I, Sittig D, Steinert M \& Aust G 2000 Expression and regulation of Regulated on Activation, Normal
$\mathrm{T}$ cells Expressed and Secreted in thyroid tissue of patients with Graves' disease and thyroid autonomy and in thyroid-derived cell populations. Journal of Clinical Endocrinology and Metabolism 85 $4758-4764$.

Tecimer T, Dlott J, Chuntharapai A, Martin AW \& Peiper SC 2000 Expression of the chemokine receptor CXCR2 in normal and neoplastic neuroendocrine cells. Archives of Pathology and Laboratory Medicine 124 520-525.

Vaddi K, Keller M \& Newton RC 1997 The Chemokine Facts Book. London: Academic Press.

Weetman AP, Bennett GL \& Wong WL 1992 Thyroid follicular cells produce interleukin-8. Journal of Clinical Endocrinology and Metabolism 75 328-330.

Wolach B, Lebanon B, Jedeikin A, Shapiro MS \& Shenkman L 1989 Neutrophil chemotaxis, random migration, and adherence in patients with hyperthyroidism. Acta Endocrinologica 121 $817-820$.

Received in final form 30 April 2001 Accepted 30 May 2001 